\title{
The use of crushed grain of spelt in wheat bread technology
}

\author{
Evgenia Khmeleva ${ }^{1}$, Natalia Berezina ${ }^{2}$, Inna Satcaeva ${ }^{3}$, Dmitry Korolev $^{1}$ and \\ Marina Chalykh ${ }^{1}$ \\ ${ }^{1}$ Oryol State University named after I.S. Turgenev, 95, Komsomolskaya st., Oryol region, 302026 \\ the Russian Federation \\ ${ }^{2}$ Orel State Agrarian University named after N. V. Parakhin, 69 Generala Rodina str., Oryol region, \\ 302019 the Russian Federation \\ ${ }^{3}$ North Ossetian State University named after K. L. Khetagurov, 44-46 Vatutina str., Vladikavkaz, \\ Republic of North Ossetia - Alania, 362025, the Russian Federation
}

\begin{abstract}
Spelt is a valuable crop, known for a long time, but little used currently. The increased interest in it is explained by the great potential of this crop, which lies in its rich chemical composition, and the possibility of using it as a source of alternative raw material in the baking industry. The possibility of using crushed spelt grain (spelt groats) in the technology of wheat bread with increased nutritional value and functional orientation is considered. A rational way of soaking spelt groats has been determined. The influence of spelt groats on the properties of the dough and quality indicators of wheat bread has been studied. A rational dosage of spelt groats has been determined, the use of which makes it possible to obtain bakery products that are as close as possible to the control sample in their physical and chemical parameters.
\end{abstract}

\section{Introduction}

The problem of improving the structure of the population nutrition by the development of mass consumption products with a high nutritional value and functional orientation is one of the most urgent in modern society and is primarily facilitated by noticeable changes in the lifestyle of the population, which have a negative impact on health. The importance of this problem is confirmed by government acts that determine the state policy in the field of healthy diet.

Bakery products are daily consumed products of some social groups and form the basis of their diet. The analysis of the nutritional value of some mass bakery products has shown that they mainly satisfy the daily energy need and are characterized by an imbalance of proteins, fats and carbohydrates, microelements, they contain a low amount of dietary fiber and have a high glycemic index.

In recent years the assortment structure of bakery products has undergone significant changes under the influence of various factors. However, the production of dietary foods and preventive nutrition products is extremely insignificant and amounts to $1.0 \%$. This is

\footnotetext{
* Corresponding author: hmelevaev@bk.ru
} 
facilitated by insufficient advertising and low concern of manufacturers who are aimed at mass production. Bakery products are easy for adjusting the nutritional value of the diet. In Russia, about 100 thousand tons of functional products are annually produced with a demand of 1-1.5 million tons according to the Institute of Nutrition of the Russian Academy of Medical Sciences (now the Federal State Budgetary Scientific Institution "Federal Research Center for Nutrition, Biotechnology and Food Safety"). It is beyond argument that the need in functional products will increase over time.

The development of technologies based on the use of grain crops while preserving the nutritional composition of the original grain, which makes it possible to create a wide assortment of products that meet modern requirements to healthy diet, is a topical area aimed at improving the functional and health-promoting properties of bakery products. And in this light, the grain crop of spelt is of interest. According to the literature spelt has richer chemical composition than modern wheat; it contains much protein that is characterized by a balanced amino acid composition [1-6], dietary fiber [7,9,10], minerals [9,10] and is of interest for the bakery industry as a source of alternative raw material for obtaining products with increased nutritional value, including a functional orientation.

The purpose of the research was to develop a technology of wheat bread with increased nutritional value using crushed spelt grain (spelt groats).

\section{Material and methods}

The objects of research are spelt groats obtained from spelt grain Triticum dicoccum (Schrank.) Schuebl., Runo variety grown in the Oryol region; bakery wheat flour of the highest grade; dough; wheat bakery products.

The research methods of quality indicators of spelt groats: moisture - according to GOST 26312.7-88; acidity - according to GOST 26971-86; the content and quality of gluten - according to GOST 27839 - 2013; the size (particle size) of groats - according to GOST 26312.4-84.

The acidity of the dough was determined by the generally accepted method [11], the structural and mechanical properties of the dough were obtained using the ST-1M Structurometer with subsequent calculation of the ultimate shear stress of the dough.

The methods of assessing the quality of bakery products: organoleptic (appearance, crumb condition, taste, flavour) and physicochemical indicators (moisture, porosity, acidity, specific volume, structural and mechanical properties of the crumb) in products were determined in $(4 \pm 1) \mathrm{h}$ after baking according to the methods specified in $[11,12]$.

\section{Results and discussion}

Since the purpose of the study was to develop a technology of wheat bread with increased nutritional value using crushed spelt grain (spelt groats), it was considered expedient at the first stage to analyze the chemical composition and quality indicators of this crop.

Spelt groats (Fig. 1) are particles of crushed spelt grains of various sizes, creamy-brown in color, without embryo and almost free from fruit and seed coats.

The chemical composition of spelt grain and its processed products is not fully covered in literary sources, despite the fact that this grain crop has a number of advantages over the widespread and used wheat. Available data vary due to grain variety, growing area, climatic conditions and harvesting. Table 1 gives the average data on the chemical composition of spelt. [1-10] 


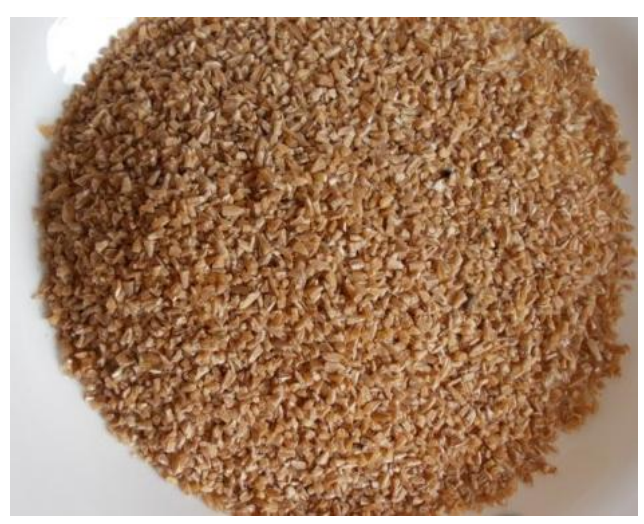

Fig. 1. Spelt groats (crushed spelt grains).

Table 1. Chemical composition of spelt grain and soft wheat.

\begin{tabular}{|l|c|c|}
\hline Indicator & Spelt grain & Soft wheat grain \\
\hline Proteins, $\%$ & 14.50 & 11.80 \\
\hline Fats, $\%$ & 2.40 & 2.20 \\
\hline Polyunsaturated fatty acids, $\%$ & 1.30 & 0.40 \\
\hline Carbohydrates, including: & 70.0 & 59.50 \\
\hline Starch, $\%$ & 53.90 & 55.50 \\
\hline Reducing sugars, $\%$ & 3.02 & 1.09 \\
\hline Cellulose, $\%$ & 5.3 & 2.00 \\
\hline Vitamins, mg: & & 0.44 \\
\hline $\mathrm{B}_{1}$ & 0.36 & 0.15 \\
\hline $\mathrm{B}_{2}$ & 0.113 & 1.15 \\
\hline $\mathrm{B}_{5}$ & 1.16 & 0.53 \\
\hline $\mathrm{B}_{6}$ & 0.23 & 37.50 \\
\hline $\mathrm{B}_{9}$, mkg & 45.00 & 10.40 \\
\hline $\mathrm{H}$ & 9.30 & 1.70 \\
\hline Ash, $\%$ & 2.10 & \\
\hline Minerals, mg: & & 108.00 \\
\hline magnesium & 136.00 & 370.00 \\
\hline phosphorus & 401.00 & 5.40 \\
\hline iron & 4.40 & 337.00 \\
\hline potassium & 338.00 & 2.79 \\
\hline zinc & 3.28 & 108.00 \\
\hline manganese & 115.00 & 29.00 \\
\hline selenium, mkg & 11.70 & \\
\hline & & \\
\hline
\end{tabular}

The analysis of the chemical composition shows the following:

- spelt is superior to wheat in protein content;

- spelt contains more simple sugars;

- spelt is rich in polyunsaturated fatty acids;

- spelt outperforms wheat in terms of dietary fiber content;

- an increased content of some vitamins (pantothenic, folic acids and choline) and minerals (magnesium, phosphorus, zinc, manganese) is revealed.

Thus, this crop with a valuable chemical composition can be recommended for use in bread baking to create bakery products with increased nutritional value.

The quality indicators of crushed spelt grain (spelt groats) have been experimentally determined. It was found that the analyzed groats have a sufficiently high acidity - 4.6 degrees, which can affect the initial acidity of the dough when adding large dosage of spelt 
groats. The moisture of groats was $12 \%$, which does not exceed the value established by GOST.

Despite the fact that in groats made from wheat (and spelt is wheat), the content and quality of gluten is not standardized and not determined, it was decided to determine the value of these indicators, since it was supposed to introduce as much spelt as possible into the bread recipe instead of wheat flour to increase nutritional value of products. To do this, the groats were preliminarily crushed to flour and then the quantity and quality of gluten were determined in a standard way. It was found that spelt groats contain $20 \%$ of raw gluten of satisfactory quality (77.5 units of the IDK device - satisfactorily weak).

To determine the granulometric composition of spelt groats, a laboratory plansifter with a set of woven-wire-cloth sieves was used. The passage through a sieve with a mesh size of $1.5 \mathrm{~mm}$ was $55 \%$, the yield from sieve No. $063-45 \%$. Thus, the crushed spelt is similar in particle size to the Artek wheat groats and is fractions of grain particles with the size of 0.6-1.5 mm.

In the production of cereal bread, one of the technological stages is the soaking of groats, which is necessary in order to achieve a certain moisture value (41\% - 43\%), which makes it possible to use groats for kneading flour dough. The dynamics of changes in the moisture value of spelt groats in the process of soaking was being determined in the work. The pre-washed groats were soaked in water in a 1: 1 ratio at a temperature of $20 \pm 2{ }^{\circ} \mathrm{C}$ (under laboratory conditions) and $37 \pm 2{ }^{\circ} \mathrm{C}$ (in a proofing cabinet). It is found that the temperature of soaking affects the process time and the period when spelt groats achieve the technological value of moisture. When groats are soaked in room conditions (temperature $20{ }^{\circ} \mathrm{C}$ ), the required humidity is reached in 1.5 hours, but soaking in a proofing cabinet (temperature $37^{\circ} \mathrm{C}$ ) shortens this process. Based on the results obtained, a rational method of soaking spelt crumbs was determined - 30 minutes at a temperature of $37^{\circ} \mathrm{C}$.

In order to create cereal bread with increased nutritional value, the following dosages of spelt groats were proposed instead of white wheat flour - 40, 50 and 60\%. Pre-soaked groats were added when kneading the dough. The dough was prepared according to straight dough procedure. The control sample was the dough kneaded without spelt groats. We controlled the change in acidity during the fermentation of the dough, as well as its structural and mechanical properties. The results are shown in Table 2 and Figure 2.

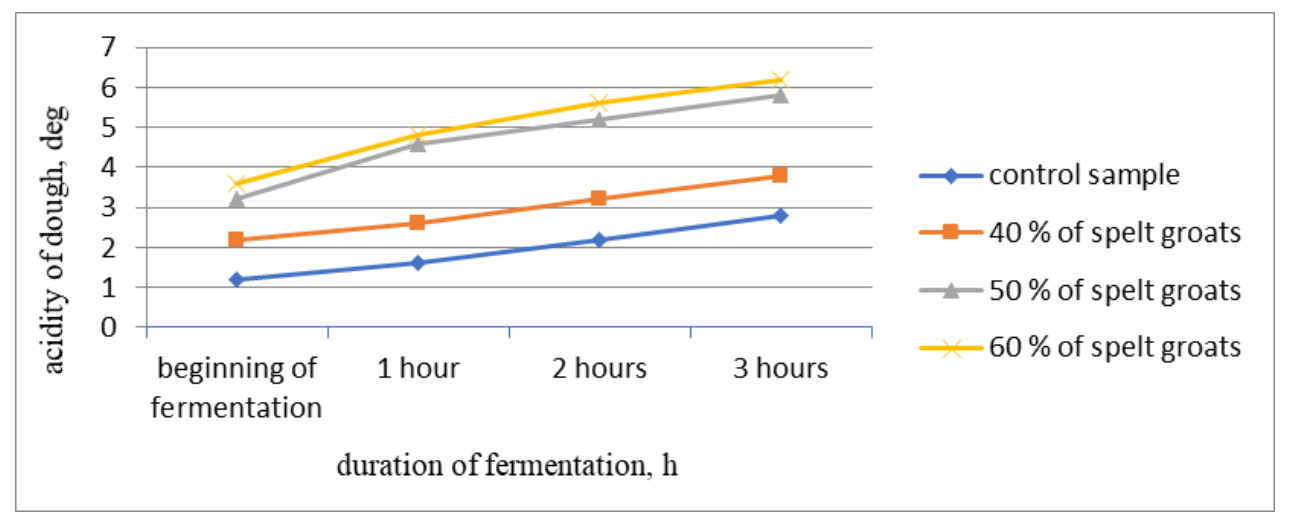

Fig. 2. The change in acidity of dough during the fermentation.

The analysis of the results obtained shows that the initial acidity of the dough when adding spelt groats increases proportionally to the dosage of the groats, which is probably due to the higher acidity of the groats themselves compared to wheat flour. So, in the control sample, the initial acidity of the test was 1.2 degrees, and in the experimental 
samples - 2.2-3.6 degrees, respectively. During fermentation, the accumulation of acidity in the test samples was more intensive than in the control one, which led to the reduction of fermentation time of the test samples (1.5-2 hours) compared to the control sample (3 hours).

Such an intensification of the technological process is possible due to the fact that additional nutrients are introduced into the dough with spelt groats, as a result of which favorable conditions are created for the development of fermenting microflora and the intensification of biochemical processes, which leads to the reduction fermentation time of ready-to-cook products.

Table 2. Structural and mechanical properties of the dough.

\begin{tabular}{|l|c|c|}
\hline \multicolumn{1}{|c|}{ Sample } & $\begin{array}{c}\text { Ultimate shear stress at the } \\
\text { beginning of fermentation, kPa }\end{array}$ & $\begin{array}{c}\text { Ultimate shear stress at the } \\
\text { end of fermentation, kPa }\end{array}$ \\
\hline Control & 0.61 & 0.49 \\
\hline $\begin{array}{l}\text { Sample with } 40 \% \text { of spelt } \\
\text { groats }\end{array}$ & 0.46 & 0.40 \\
\hline $\begin{array}{l}\text { Sample with 50 \% of spelt } \\
\text { groats }\end{array}$ & 0.31 & 0.29 \\
\hline $\begin{array}{l}\text { Sample with } 60 \% \text { of spelt } \\
\text { groats }\end{array}$ & 0.27 & 0.25 \\
\hline
\end{tabular}

The analysis of the structural and mechanical properties of the dough during fermentation shows that the introduction of spelt groats instead of wheat flour leads to a decrease of the ultimate shear stress indicator of the dough at the beginning of fermentation compared to the control sample. This is due to the fact that groats destroy the cohesion of the gluten framework of the wheat dough, which leads to some deterioration in the rheological characteristics of the dough. In the course of fermentation, the viscosity of the control dough and test samples naturally decreases, colloidal changes in proteins occur, and the activity of enzymes increases.

To study the effect of spelt groats on the quality indicators of wheat bread, some samples of bread were baked in the laboratory (Fig. 3).

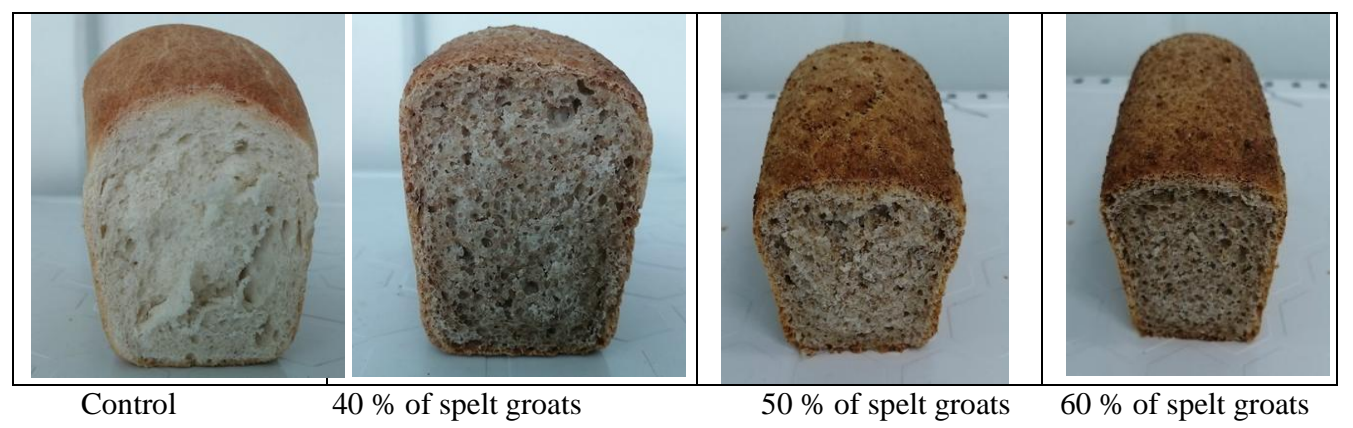

Fig. 3. Bread samples.

The organoleptic evaluation of baked bread samples shows that with an increase in the dosage of spelt groats in the recipe instead of wheat flour, such indicators as the taste and flavour of bread change, they become rich and brisk, the surface of the crust looks rough, the structure of the crumb differs from that of plain bread made from flour - heterogeneous, interspersed with grain particles, which is characteristic of products with grain and attracts 
the consumer. It should be noted that bread with a dosage of spelt groats of $60 \%$ instead of wheat flour had damp, low elastic crumb that took the shape of balls when chewed.

Table 3. Physical and chemical indicators of bread quality.

\begin{tabular}{|l|c|c|c|c|}
\hline \multicolumn{1}{|c|}{ Indicator } & Control & $\begin{array}{c}\text { Sample with } \\
\mathbf{4 0} \% \text { of } \\
\text { spelt groats }\end{array}$ & $\begin{array}{c}\text { Sample with } \\
\mathbf{5 0} \% \text { of } \\
\text { spelt groats }\end{array}$ & $\begin{array}{c}\text { Sample with } \\
\mathbf{6 0} \% \text { of spelt } \\
\text { groats }\end{array}$ \\
\hline Moisture, \% & 39.0 & 40.2 & 41.5 & 42.0 \\
\hline Acidity, degree & 2.8 & 3.6 & 3.6 & 3.8 \\
\hline Specific volume, sm ${ }^{3}$ g & 2.35 & 2.23 & 2.26 & 2.28 \\
\hline Porosity, \% & 70.0 & 68.0 & 67.0 & 65.0 \\
\hline $\begin{array}{l}\text { Structural and mechanical } \\
\text { characteristics of crumb, } \\
\text { mm: }\end{array}$ & 21.6 & 15.2 & 14.6 & 12.8 \\
$\Delta \mathrm{H}_{\text {total }}$ & 3.5 & 3.9 & 2.5 & 3.1 \\
\hline$\Delta \mathrm{H}_{\text {plastic }}$ & 18.1 & 11.3 & 12.1 & 9.7 \\
\hline$\Delta \mathrm{H}_{\text {elastic }}$ & & & \\
\hline
\end{tabular}

When analyzing the physical and chemical indicators of the quality of bread, it was revealed that an increase in the dosage of spelt groats in the recipe leads to a slight decrease in the specific volume and porosity of the bread due to the fact that the groats added to the dough do not allow to form the complete gluten frame of the wheat dough, breaking its cohesion. And also crushed grain particles in the dough make it heavier, reducing the gasholding capacity of the dough, which ultimately leads to a decrease in the specific volume and porosity of the finished bread. Thus, the porosity of bread decreases by $2.0 \%-5.0 \%$, the specific volume - by $3.0 \%-5.1 \%$ compared to the control sample. With an increase in the dosage of spelt groats, the moisture and acidity of the crumb of wheat bread increases, which is connected with the water absorption capacity and acidity of the groats themselves.

Thus, on the basis of the studies carried out and taking into account the enrichment of bread made from wheat flour, a rational dosage of spelt groats was found - 50\% instead of wheat flour, the use of which makes it possible to obtain bakery products that are as close as possible in their physical and chemical parameters to the control sample.

Calculation of the nutritional value of the developed bread shows that the consumption of $150 \mathrm{~g}$ of such bread per day covers the need of proteins by $20.6 \%$, fats by $7.0 \%$, carbohydrates by $19.8 \%$, dietary fiber by $23.3 \%$. The introduction of spelt into the recipe of wheat bread changes its chemical composition, in particular, the amount of dietary fiber increases, which allows to classify the proposed products as functional, since the content of the functional ingredient, which is dietary fiber, is more than $15 \%$ of the daily need.

\section{Conclusions}

Based on the comprehensive research carried out, a recipe and technology for the production of bread from white wheat flour with increased nutritional value and functional orientation with the addition of crushed spelt grain (spelt groats) have been developed. 


\section{References}

1. P. Konvalina, I. Capouchova, Z. Stehno, J. of Nutrition and Food Engineering, 7, 370 (2013) K.J.Chua, A.S.Mujumdar, M.N.A.Hawlader, S.K,Chou,J.C. Ho, Food Res. Int., 34, 721 (2001)

2. P. N. Malchikov, V. I. Zotikov, V. S. Sidorenko, E. N. Shabalkina, N. G. Myasnikova, Legumes and cereals, 3, 101 (2016)

3. N.M. Popova, Vestnik KrasGAU, 5,15 (2017)

4. J. Lachman, M. Orsak, V. Pive K. Jiru, Plant Soil and Environment, 9, 15 (2012)

5. Z. Stehno, Czech Journal of Genetics and Plant Breeding, 43, 113 (2007)

6. M. Mangova, National Scientific Conference "60 years of Fruit Growing Institute Plovdiv"(Bulgaria: Plovdiv, 2014)

7. O.V. Chugunova, E. V. Kryukova, Scientific Bulletin, 3, 90 (2015)

8. E. Suchowilska, M. Wiwart, W. Kandler, Plant soil environment, 58, 141 (2012)

9. I.A. Bazhenova, Research of technological properties of spelt grain (Triticum dicoccum schrank.) and development of culinary products using it (Dis ... cand. of technical sciences), 109 (2004)

10. V.V. Yurkov, Izvestiya VUZov. Food technology, 1, 23 (2005)

11. S.Ya. Koryachkina, N.V. Labutina, N.A. Berezina, E.V. Khmeleva, Quality control of raw materials, semi-finished products and bakery products, (2012)

12. N.A. Berezina, A.V. Artemov, I.A. Nikitin, A.A. Budnik, International Journal of Advanced Computer Science and Applications. 10 (5), 137-143 (2019) 